\title{
Open loop control of a stepping motor with step loss detection and stall detection using back-EMF based load angle estimation
}

\author{
Stijn Derammelaere ${ }^{1}$, Florian Verbelen ${ }^{1}$ and Kurt Stockman ${ }^{1}$
}

\begin{abstract}
Stepping motors are the most used electrical machines for low power positioning. The drive controls the machine so that the rotor performs a fixed angular displacement after each step command pulse. Counting the step command pulses enables open-loop positioning. The vast majority of the stepping motor systems is driven in open-loop. When the rotor hits an obstacle stall occurs. Step loss due to overload is another typical problem with stepping motor driven systems. Both phenomena are not detected in open-loop which causes loss of synchronism. In this paper, a sensorless load angle estimator is used to detect step loss and stall. This algorithm is based on the typical stepping motor drive algorithms and does not depend on mechanical load parameters. The method therefore has a broad industrial relevance.
\end{abstract}

\section{INTRODUCTION}

The two-phase hybrid stepping motor principle is illustrated in Fig. 1 [1], [2]. The stator is equipped with concentrated windings while the multitoothed rotor is magnetized by means of permanent magnets. The rotor teeth are attracted by the excited stator phase. When a new full-step command pulse is given, the excitation of one phase is released while a second phase is excited. In half- and micro-stepping algorithms, two phases are excited simultaneously in order to increase the number of rotor position steps in a single revolution.

By counting the step command pulses, open-loop positioning is achieved. The fact that an expensive sensor is not needed, makes these motors very appealing for industrial and domestic applications. However, increasing mechanical loads and dynamic requirements could result in step loss or even worse a complete stall of the rotor. These open loop stepping motor drive methodologies do not detect step loss or stall. In these cases it is quite common that the open-loop control continues to send unnecessary and even unwanted step command pulses. It is possible that the mechanical structure repeatedly hits an obstacle resulting in wear, noise and vibrations. Certain homing algorithms will purposefully drive the mechanism against an obstacle to obtain a reference position. Therefore, a feedback mechanism indicating stall or step loss is very useful in stepping motor applications. Using a mechanical position sensor to monitor the rotor position as in [3], would increase the cost and complexity of the system and omits the straightforward open loop control.

One particular commercial stepping motor drive algorithm [4]-[6] detects stall and step loss, based on back-EMF samples. The stator phase voltage is measured during the interval the phase current setpoint is zero. When the actual

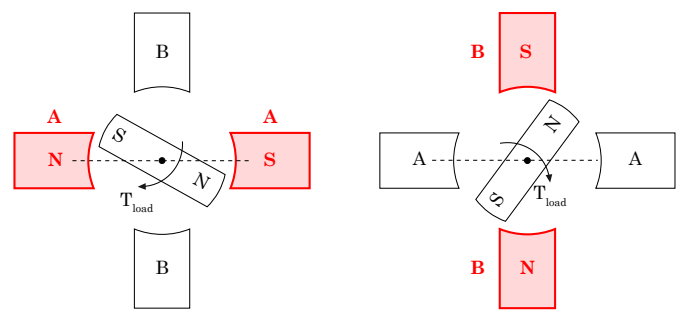

(a) Full Step principle

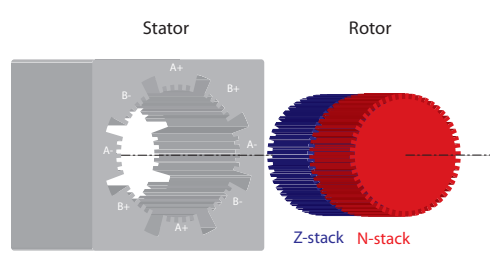

(b) Hybrid stepping motor construction

Fig. 1. Stepping motor principle

phase current decayed to zero, there will be no more resistive voltage drop and no inductive coil voltage and the measured phase voltage equals the back-EMF induced in the stator phase. However, at higher rotational speeds or coils with a high inductance, the current decay takes too long and the back-EMF cannot be sampled correctly during the interval the phase current command is zero.

A sensorless estimation algorithm as described in literature could be a more reliable option to detect stall and step loss without a mechanical position sensor. Research concerning sensorless control for PMSM and induction machines is getting mature [7]-[12]. Research efforts have also been made to implement sensorless control for stepping motors [13]-[15]. One particular sensorless algorithm estimates the load angle [16]. In contrast to more complex observer algorithms this estimator does not depend on mechanical load parameters and is characterized by a low computational cost. Because of these practical advantages this algorithm is used in this research. The load angle itself is discussed in section II and the estimator is described in section III. Measurements of the maximum load angle under stable operation over the whole operating range are discussed in section IV. These measurements are used to determine a threshold load angle value which indicates stall or step loss. The stall and step loss detection algorithm itself is analyzed in section $\mathrm{V}$. 

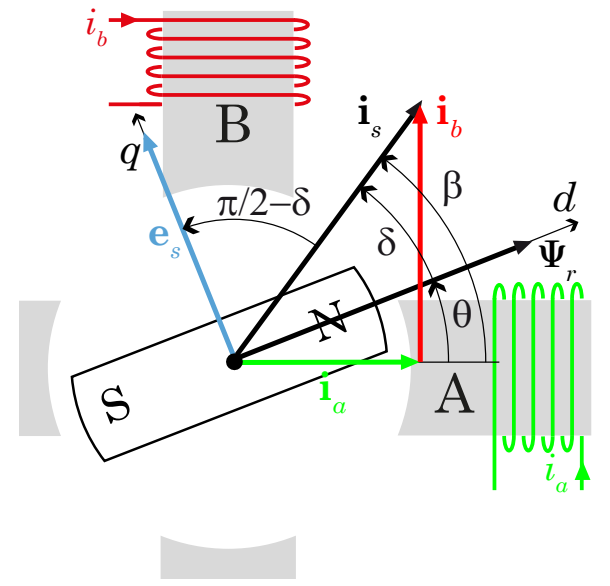

Fig. 2. Back-EMF, current and flux vectors

\section{LOAD ANGLE}

The formula describing the electromagnetic motor torque is essential to have the necessary understanding in the stepping motor drive principle. The electromagnetic torque vector $\mathbf{T}_{\text {motor }}$ can be determined based on the interaction between the stator flux linkage space vector $\boldsymbol{\Psi}_{s}$ and the stator current space vector $\mathbf{i}_{s}$ [17].

$$
\mathbf{T}_{\text {motor }}=\Psi_{s} \times \mathbf{i}_{s}
$$

Neglecting saturation, the stator flux linkage space vector $\boldsymbol{\Psi}_{s}$ can be written as the sum of the stator flux linkages, established by the two stator currents and the permanentmagnet rotor flux $\boldsymbol{\Psi}_{r}$. In the $d q$-reference frame fixed to the rotor flux, illustrated in Fig. 2, the electromagnetic torque can be written as:

$$
\mathbf{T}_{\text {motor }}=\left(\boldsymbol{\Psi}_{r}+\mathbf{i}_{d} \cdot L_{d}+\mathbf{i}_{q} \cdot L_{q}\right) \times \mathbf{i}_{s}
$$

The electromagnetic torque value can be written as a function of $i_{s}$ and the load angle $\delta$, defined as the angle between $\mathbf{i}_{s}$ and the rotor flux $\boldsymbol{\Psi}_{r}$ :

$$
T_{\text {motor }}=\Psi_{r} \cdot i_{s} \cdot \sin (\delta)+\frac{L_{d}-L_{q}}{2} \cdot i_{s}^{2} \cdot \sin (2 \delta)
$$

The first term in (3) describes the torque generated by the interaction between the permanent-magnet rotor flux $\boldsymbol{\Psi}_{r}$ and the stator current $\mathbf{i}_{s}$. This term depends on the sine of the load angle $\delta$. Because of the multitoothed rotor and stator construction of a hybrid stepping motor, the reluctance effect will increase the maximum electromagnetic torque. This reluctance effect is represented by the second term in (3) and varies sinusoidally with twice the load angle $\delta$. To quantify both effects, the motor torque is measured, using the test rig depicted in Fig. 6. While the rotor is blocked the load angle $\delta$ is modified by changing the phase current setpoints $i_{a}^{*}$ and $i_{b}^{*}$. For a current amplitude of $60 \%$ and $100 \%$ of the nominal current, measurement results are given in Fig. $4^{1}$. The dominant torque component is the component generated by the permanent-magnet effect.

To illustrate the behavior of the load angle, measurements are performed at different speed and torque levels at maximum current. Fig. 5 illustrates these results for a half-step operation mode. The load angle increases when the load torque increases. A higher rotational speed also results in an increased load angle. The latter is due to a higher friction torque in the test setup.

\section{LOAD ANGLE ESTIMATION}

Using Lenz's law the back-EMF voltage vector $\mathbf{e}_{s}$, induced by the rotor flux $\boldsymbol{\Psi}_{r}$, can be written as:

$$
\mathbf{e}_{s}=C \cdot \frac{\mathrm{d} \boldsymbol{\Psi}_{r}}{\mathrm{~d} t}
$$

This implies a phase lead of $\pi / 2 \mathrm{rad}$ between the backEMF vector $\mathbf{e}_{s}$ and the flux vector $\boldsymbol{\Psi}_{r}$ as illustrated in Fig. 2. From Fig. 2 it follows that the angle between the current vector $\mathbf{i}_{s}$ and the back-EMF vector $\mathbf{e}_{s}$ is $\pi / 2-\delta$. Because the current can be measured easily, estimating the load angle can be reduced to a problem where the back-EMF signal has to be estimated.

The stator phases can be modeled as [2]:

$$
u_{s}=R_{s} \cdot i_{s}+L_{s} \cdot \frac{\mathrm{d} i_{s}}{\mathrm{~d} t}+e_{s}
$$

When the stator phases are modelled one could consider the position dependency of the inductances [1] caused by the multi toothed rotor and stator construction ( Fig. 1 ). However, [1] suggests to neglect the inductance variation and literature concerning stepping motor control [15], [18] uses a constant inductance $L_{s}$ and neglects the difference between $L_{d}$ and $L_{q}$.

\footnotetext{
${ }^{1}$ All angular values are given in electrical radians. For a machine consisting of $p$ pole pairs this means the actual mechanical angle $\theta_{\text {mech }}=\theta / p$
} 


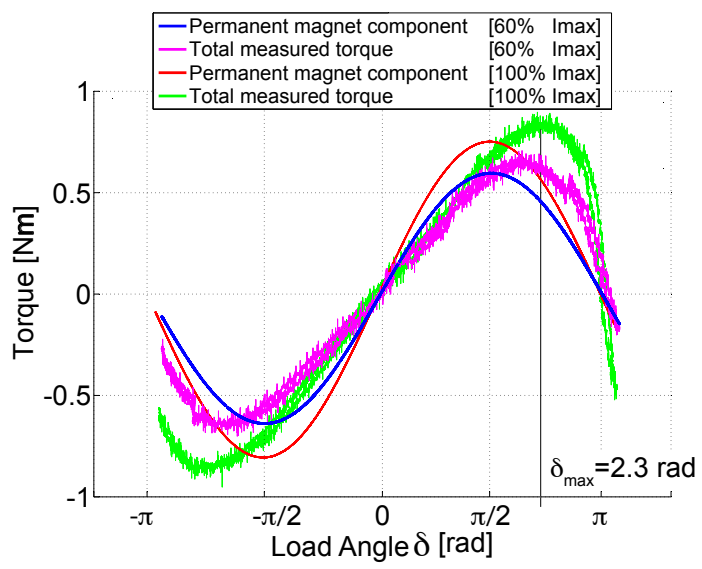

Fig. 4. Measured torque - load angle relation for $60 \%$ and $100 \%$ nominal current $I_{\max }$

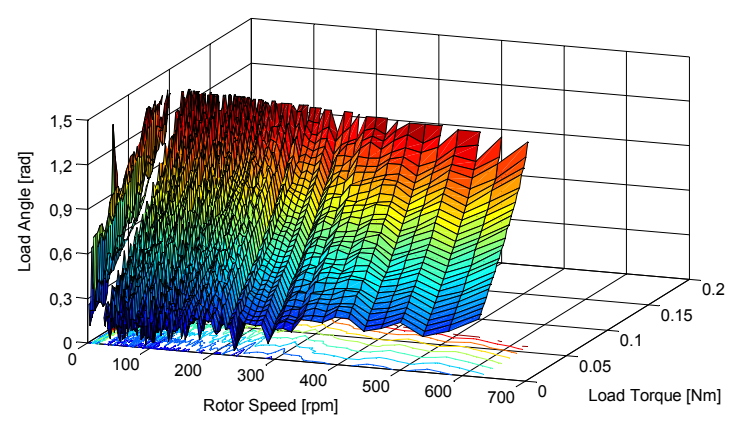

Fig. 5. Measured load angle $\delta$ for different torque and speed setpoints at nominal current

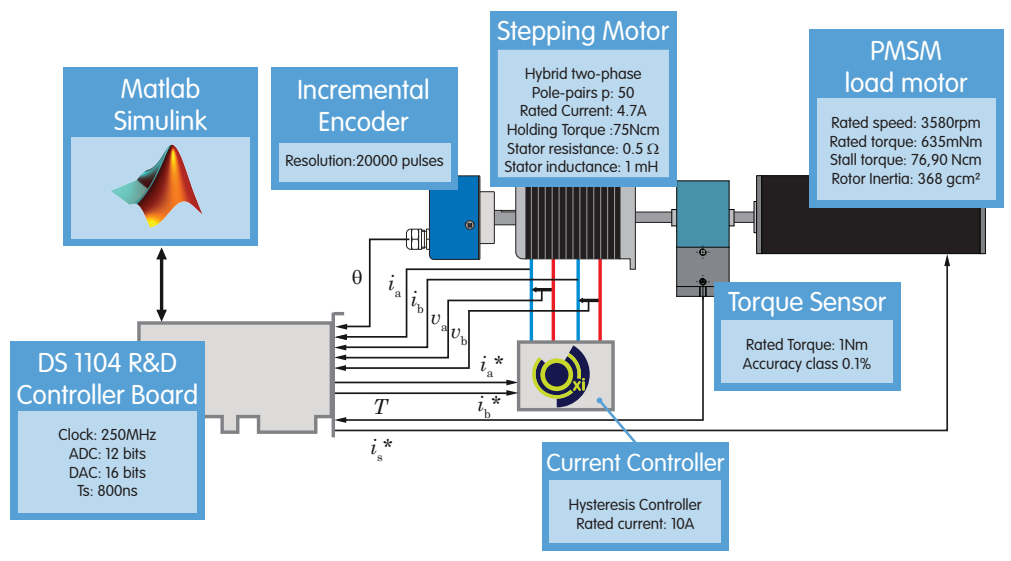

Fig. 6. Dedicated test rig setup and parameters of the equipment

[16] suggests to write (5) in the frequency domain:

$$
E_{s}(j \omega)=U_{s}(j \omega)-j \omega \cdot L_{s} \cdot I_{s}(j \omega)-R_{s} \cdot I_{s}(j \omega)
$$

Simulations and measurements discussed in [16] show that the load angle can be estimated based on the fundamental waveform of the electrical signals. Fig. 7 illustrates the fundamental current signal derived from the measured current. Equation (6) could then be written at fundamental pulsation $\omega_{1}$. As illustrated in Fig. 3 the step command pulses determine the rotational speed and therefore the fundamental pulsation $\omega_{1}$ is known. In [16] it is suggested to use the sliding discrete Fourier transform (SDFT) [19][21] to calculate the fundamental voltage $U_{s 1}$ and current $I_{s 1}$ components based on consecutive measurement samples (shown in Fig. 7) in a computationally efficient manner. For a period of $N$ samples the $z$-domain transfer function of the $k^{\text {th }}$ order SDFT is:

$$
\frac{1-z^{-N}}{1-e^{j 2 \pi \cdot \frac{k}{N}} \cdot z^{-1}}
$$

Finally the (6) is used to determine the fundamental back-
EMF $E_{s 1}$ based on the fundamental current $I_{s 1}$ and voltage $U_{s 1}$. According to 2 the estimated load angle $\hat{\delta}$ can then be written as:

$$
\hat{\delta}=\frac{\pi}{2}-\left(\angle\left(E_{s 1}\right)-\angle\left(I_{s 1}\right)\right)
$$

\section{CRITICAL LOAD ANGLE IN OPERATION}

The measurements in Fig. 4 indicate the generated torque increases for a rising load angle up to approximately 2.3 rad at full current. If the load angle exceeds this $\delta_{\max }$ value the generated torque drops which results in step loss. As a stepping motor is typically driven in open loop at a certain imposed speed it is reasonable to assume the machine should be driven at a safe load angle value somewhat lower then $\delta_{\max }$. In this research, the critical load angle at which the machine can be driven in open loop at constant current for a certain load and speed setpoint is measured for the whole operating range of the motor. To do so, the current level is lowered in steps as indicated in Fig. 8. When a current reduction leads to step loss, the load angle at the previous current level is registered as the critical one. Fig. 9 depicts 


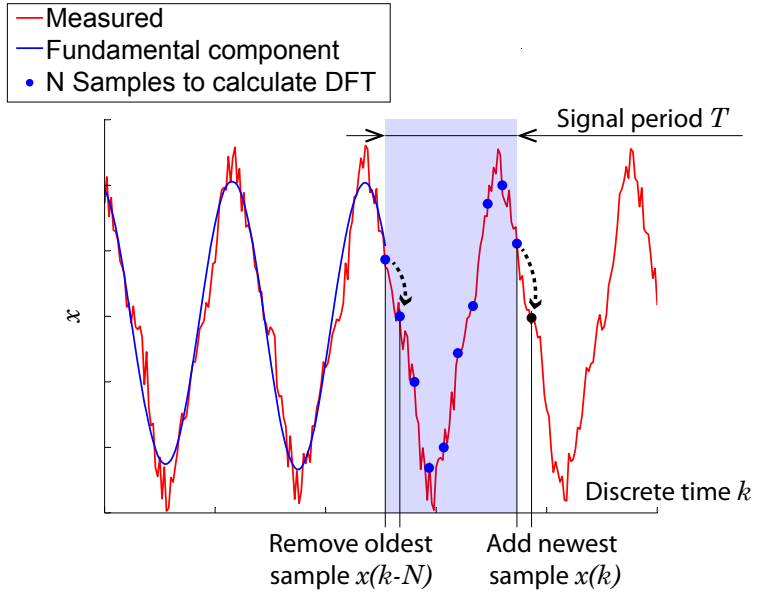

Fig. 7. Determining the fundamental waveform based on measurements

the critical load angle values for all load torques and speed setpoints within the operating range.

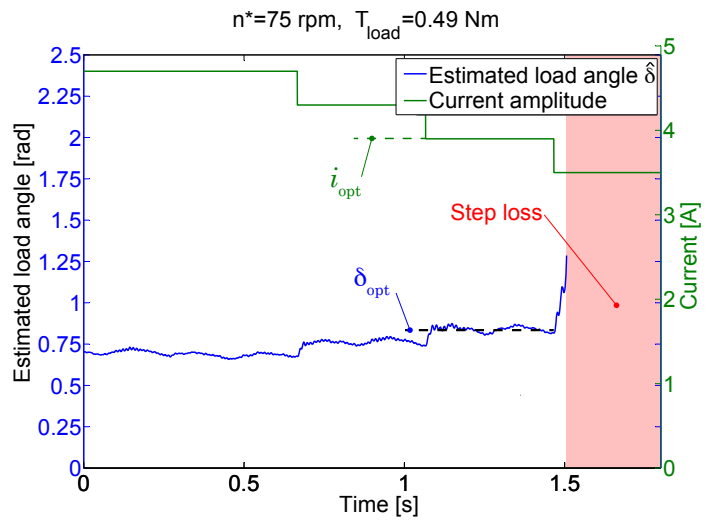

Fig. 8. Piece wise current reduction until step loss occurs to determine the optimal load angle $\delta_{\text {opt }}$

From Fig. 9 it follows that the actual optimal load angle for a loaded machine rotating at an imposed speed is maximum $1.48 \mathrm{rad}$.

\section{STALL}

Open loop stepping motor drive algorithms will continue sending step command pulses when step loss or stall occurs. As indicated in Fig. 10, this results in an increasing load angle.

An increasing load angle can be caused not only by a stall or step loss but also by a decreasing current or rising load torque. However, as measurements (Fig. 9) indicate the load angle will never be higher than 1.48 rad in the stable operation range. When the load angle exceeds the critical value of $1.48 \mathrm{rad}$ it is certain that there is a loss of synchronism between the position of the current excitation vector and the actual rotor position. In this paper the actual threshold value

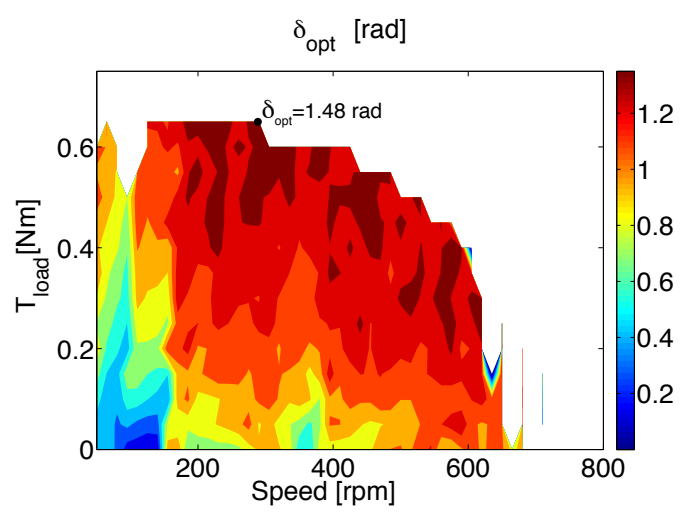

Fig. 9. Optimal load angle $\delta_{\text {opt }}$ in the entire operating range of the stepping motor driven in micro-stepping

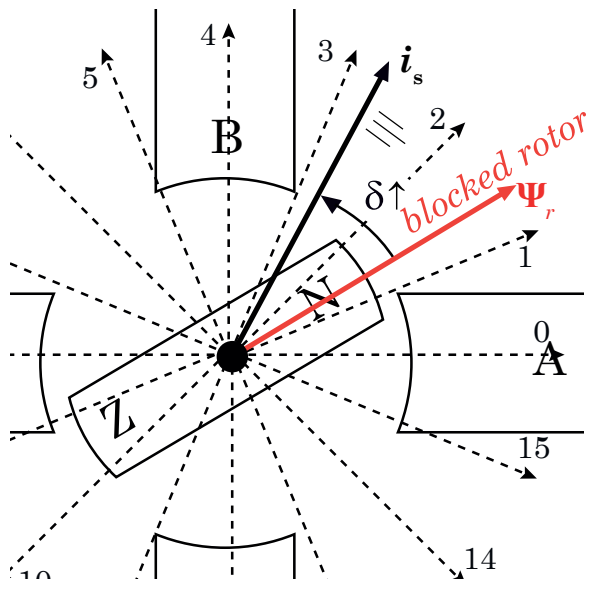

Fig. 10. Step commands (dashed lines $0,1,2,3,4, \ldots$ ) sent when the rotor (fluxvector $\boldsymbol{\Psi}_{r}$ ) is stalled result in an increased load angle $\delta$

is chosen at $\pi / 2 \mathrm{rad}$. This is because the theoretical optimal load angle is $\pi / 2$ when only the permanent magnet effect in (3) is considered.

The test rig of Fig. 6 is equipped with a brake which is used to instantly stall the stepping motor rotor. Moreover, a load motor is available to overload the stepping motor which results in step loss. Fig. 12 shows both the actual measured load angle and the estimated value for an algorithm running with a cycle time of $0.8 \mathrm{~ms}$. When the estimated load angle exceeds the critical value of $\pi / 2$ the algorithm indicates the occurrence of a stall or step loss. When a stall or step loss is detected the rotation of stator flux vector caused by the step command pulses should be stopped. This means the speed command becomes zero. As the estimation algorithm is based on the back-EMF and the signal period, the algorithm is not able to estimate the load angle for a stopped machine. Fig. 12 illustrates the load angle estimation is stopped when the load angle threshold is exceeded.

The stall or step loss detection is followed by stopping the rotation of the stator flux vector. This means the position of 
this vector is not longer determined by the step command pulses. The best actions hereafter depend on the application and requirements. When the step loss occurred due to an overloaded machine it makes sense to keep the current amplitude at its maximum level to hold the rotor at the position where the overload took place. In these cases, it could even be possible to drive the motor at a lower speed. However, when the threshold is exceeded due to a stall it is more interesting to remove the excitation of the machine. Another possible response when the mechanism hits an obstacle is reversing the direction.

Because the estimated load angle is based on all current and voltage measurement samples of the previous signal period, the estimated load angle will be delayed compared to the real load angle. This means the load angle is almost $\pi$ rad when the estimated value exceeds the threshold of $\pi / 2$. In case of a stall it could therefore be interesting to set at least 2 full-steps back, depicted in Fig. 11, to release the pressure of the mechanism at the obstacle and maintain the synchronism between step command pulses and actual rotor position.

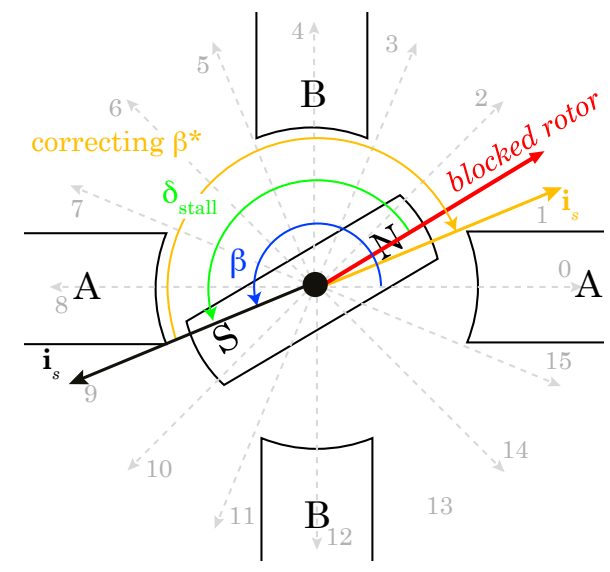

Fig. 11. Suggested compensation when following a stall detection

\section{CONCLUSIONS}

Open loop positioning is possible with a stepping motor as step command pulses are used to determine the rotor flux position. When this open loop drive algorithm is extended with a sensorless stall and step loss detection, a robust stepping motor drive system is obtained without using an encoder. In this paper, a load angle estimator is used. This sensorless algorithm only relies on electrical motor parameters and uses the speed setpoint, determined by the step command pulses, to estimate the load angle. Measurements were conducted and discussed to determine the best load angle threshold. When this threshold is exceeded a stall or step loss occurred. Depending on the application, the drive algorithm could react in different ways on a stall or step loss to recover synchronism between the stator current vector and rotor position vector.

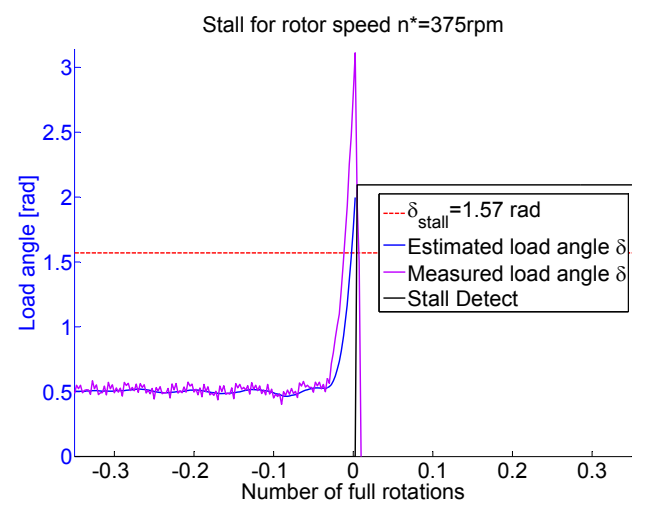

(a) Stall at $375 \mathrm{rpm}$

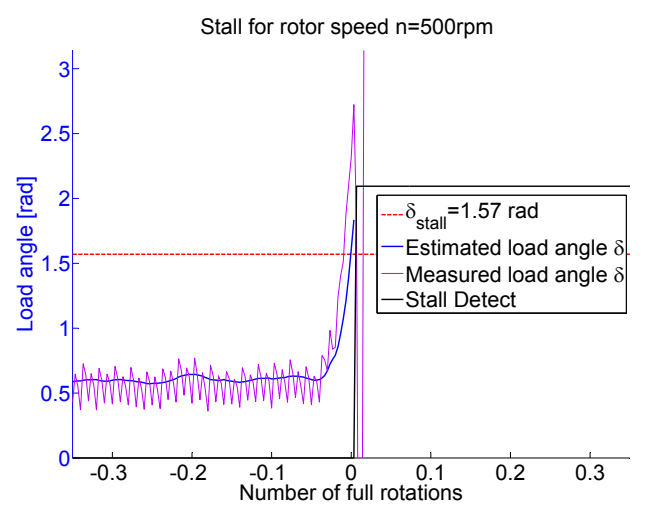

(b) Stall at $500 \mathrm{rpm}$

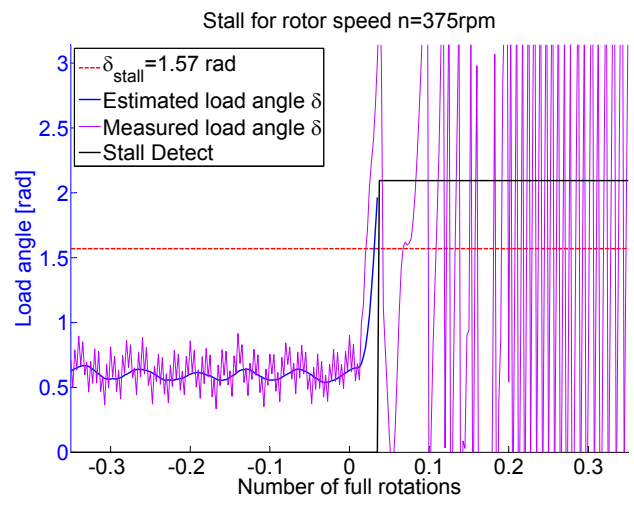

(c) Step loss due to a load torque increase

Fig. 12. load angle when step loss occurs 


\section{REFERENCES}

[1] C. Kuert, M. Jufer, and Y. Perriard, "New method for dynamic modeling of hybrid stepping motors," in Conference Record of the Industry Applications Conference, 37th IAS Annual Meeting, vol. 1, 2002, pp. 6-12.

[2] S. Derammelaere, B. Vervisch, F. De Belie, J. Cottyn, G. Van den Abeele, P. Cox, K. Stockman, and L. Vandevelde, "A nonlinear and linear model of a hybrid stepping motor," in ELECTRIMACS, 2011.

[3] Y. Khemissi and A. Abdulwahab, "Control Using Sliding Mode of Two Phase Stepper Motor," in Second International Conference on Computer Engineering and Applications (ICCEA), vol. 1, 2010, pp. 42-47.

[4] ON Semiconductor, "Micro-Stepping Stepper Motor Bridge Controller," p. 41, 2011.

[5] P. Cox and B. Decock, "Patent EP 1968183 A1: Output contact for feedback in integrated circuit motor driver," 2008.

[6] S. Derammelaere, L. Carlier, B. Vervisch, C. Debruyne, K. Stockman, L. Vandevelde, P. Cox, and G. Van den Abeele, "The opportunities of two-phase hybrid stepping motor back EMF sampling," in IEEE ECCE Energy Conversion Congress and Exposition, 2011, pp. 83-87.

[7] Y. Hua, M. Sumner, G. Asher, Q. Gao, and K. Saleh, "Improved sensorless control of a permanent magnet machine using fundamental pulse width modulation excitation." IET Electric Power Applications, vol. 5, no. 4, pp. 359-370, Apr. 2011.

[8] O. Wallmark, J. Galic, and H. Mosskull, "Sensorless control of permanent-magnet synchronous motors adopting indirect self-control." IET Electric Power Applications, vol. 6, no. 1, pp. 12-18, Jan. 2012.

[9] G. Foo and M. F. Rahman, "Sensorless vector control of interior permanent magnet synchronous motor drives at very low speed without signal injection." IET Electric Power Applications, vol. 4, no. 3, pp. 131-139, Mar. 2010.

[10] T. F. Chan, W. Wang, P. Borsje, Y. K. Wong, and S. L. Ho, "Sensorless permanent-magnet synchronous motor drive using a reduced-order rotor flux observer." IET Electric Power Applications, vol. 2, no. 2, pp. 88-98, Mar. 2008.
[11] F. De Belie, P. Sergeant, and J. Melkebeek, "A sensorless PMSM drive using modified high-frequency test pulse sequences for the purpose of a discrete-time current controller with fixed sampling frequency," MATHEMATICS AND COMPUTERS IN SIMULATION, vol. 81, no. 2 pp. 367-381, 2010.

[12] F. M. L. De Belie, P. Sergeant, and J. A. Melkebeek, "A Sensorless Drive by Applying Test Pulses Without Affecting the Average-Current Samples," IEEE Transactions on Power Electronics, vol. 25, no. 4, pp. 875-888, 2010.

[13] M. Defoort, F. Nollet, T. Floquet, and W. Perruquetti, "A Third-Order Sliding-Mode Controller for a Stepper Motor," IEEE Transactions on Industrial Electronics, vol. 56, no. 9, pp. 3337-3346, 2009.

[14] W. Kim and C. C. Chung, "Novel Position Detection Method for Permanent Magnet Stepper Motors Using Only Current Feedback,' IEEE Transactions on Magnetics, vol. 47, no. 10, pp. 3590-3593, 2011.

[15] M. Bendjedia, Y. Ait-Amirat, B. Walther, and A. Berthon, "Position Control of a Sensorless Stepper Motor," IEEE Transactions on Power Electronics, vol. 27, no. 2, pp. 578-587, 2012.

[16] S. Derammelaere and K. Stockman, "US provisional application, entitled Systems and methods for position detection," 2013.

[17] P. Vas, Sensorless vector and direct torque control. New York: Oxford University Press, 1998

[18] K.-H. Tsui, N. Cheung, and K.-W. Yuen, "Novel Modeling and Damping Technique for Hybrid Stepper Motor," IEEE Transactions on Industrial Electronics, vol. 56, no. 1, pp. 202-211, Jan. 2009.

[19] E. Jacobsen and R. Lyons, "The sliding DFT," IEEE Signal Processing Magazine, no. March, 2003.

[20] — "An Update to the Sliding DFT," IEEE Signal Processing Magazine, no. January, pp. 1-2, 2004.

[21] K. Duda, "Accurate, Guaranteed Stable, Sliding Discrete Fourier Transform [DSP Tips \& Tricks]," IEEE Signal Processing Magazine, vol. 27 , no. 6 , pp. 124-127, 2010. 